\title{
Effect of Increased Pancreatic Islet Norepinephrine, Dopamine and Serotonin Concentration on Insulin Secretion in the Golden Hamster
}

\author{
R. T. Zern, J. L. Bird, and J. M. Feldman \\ Durham Veterans Administration Medical Center and Division of Endocrinology, Department of Medicine, \\ Duke University Medical Center, Durham, North Carolina, USA
}

Summary. The purpose of this study was to determine if increased concentrations of pancreatic islet norepinephrine, dopamine, or serotonin alter insulin secretion. Golden hamsters received intraperitoneal injections of the norepinephrine precursor DLthreo-dihydroxyphenylserine, the dopamine precursor L-3,4-dihydroxyphenylalanine, or the serotonin precursor 5-hydroxytryptophan with and without pretreatment of the hamsters with the monoamine oxidase inhibitor tranylcypromine. Administration of the monoamine precursors to animals pretreated with tranylcypromine resulted in a mean increase in plasma glucose of $192 \%$ and a mean decrease in plasma insulin of $58 \%$. Using a collagenase isolation technique, islets from control and treated animals were evaluated for monoamine content and insulin secretory capacity. The monoamine concentrations in control islets, in $\mu \mathrm{mol} / \mathrm{kg}$ wet weight, were: norepinephrine $42 \pm 8$; dopamine $8 \pm 2$; and serotonin $26 \pm 9$. Administration of the appropriate precursor to control hamsters resulted in a 1.9-fold (norepinephrine), 6-fold (dopamine), and 22-fold (serotonin) increase in monoamines. There was no alteration in the glucose $(16.3 \mathrm{mmol} / \mathrm{l})$-stimulated in vitro insulin secretion from islets obtained from these hamsters. Administration of the precursors to hamsters pretreated with tranylcypromine resulted in a 3.5-fold (norepinephrine), 22-fold (dopamine), and 59-fold (serotonin) increase in monoamines. Glucose-stimulated in vitro insulin secretion from islets obtained from these hamsters was completely blocked. This study suggests that high concentrations of norepinephrine, dopamine, and serotonin in the pancreatic islets can decrease glucose-stimulated insulin secretion.

Key words: Insulin secretion, golden hamsters, pancreatic islets, norepinephrine, dopamine, serotonin, monoamine oxidase, DL-threo-dihydroxyphenylserine, L-3,4-dihydroxyphenylalanine, 5-hydroxytryptophan, tranylcypromine.

The administration of exogenous monoamines such as norepinephrine, dopamine and serotonin inhibits both in vivo and in vitro pancreatic insulin secretion [1]. Histochemical studies have indicated the presence of these monoamines in the pancreatic islets of many species [2]. The islets of the golden hamster contain norepinephrine in adrenergic nerve plexuses, but there is no evidence histochemically of dopamine or serotonin [2]. Recent studies, however, utilizing radioenzymatic assays, demonstrate a substantial concentration of dopamine and serotonin even in the islets of the hamster $[3,4]$. These observations raise the possibility that intracellular monoamines may play a significant role in the regulation of insulin secretion.

Using histochemical techniques, investigators have demonstrated that the islet dopamine content of mice is increased by the administration of the dopamine precursor L-3,4-dihydroxyphenylalanine (L-DOPA) and that the islet serotonin content of mice is increased by the administration of the serotonin precursor 5-hydroxytryptophan $[5,6]$. It has also been demonstrated that in hamster islets the uptake of the monoamine precursors L-DOPA and 5-hydroxytryptophan was 3 -fold greater than the uptake of their respective monoamines [7].

In the present study, the relationship between the monoamine concentration and insulin secretion of golden hamster islets has been evaluated. The concentration of norepinephrine, dopamine and serotonin in the pancreatic islets was increased by adminis- 
tering respectively the monoamine precursors $\mathrm{DL}$ threo-dihydroxyphenylserine (DOPS), L-DOPA or 5-hyroxytryptophan to normal hamsters and to hamsters who were pretreated with the monoamine oxidase inhibitor tranylcypromine $[3,4,8]$. The animals were sacrificed and their islets isolated. The monoamine content and the insulin secretory capacity of the islets was then measured with sensitive and specific radioenzymatic and radioimmunoassay techniques.

\section{Materials and Methods}

\section{Materials}

The following chemicals were purchased from commercial sources: DL-threo-dihydroxyphenylserine (DOPS), L-3,4-dihydroxyphenylalanine (L-DOPA), 5-hydroxytryptophan, S-acetyl coenzyme A, N-acetyl-5-methoxytryptamine (melatonin) (Sigma Chemical Co., St. Louis, MO); collagenase, class IV (Worthington Biochemical Co., Freehold, NJ); tryptamine bisuccinate (side chain-2- ${ }^{14} \mathrm{C}$ ) with specific activity (spec. act.) of $60 \mathrm{mCi} / \mathrm{mmol}$ and S-adenosyl-L-( ${ }^{3} \mathrm{H}$-methyl)-methionine $\left({ }^{3} \mathrm{H}-\mathrm{SAM}\right)$ with spec. act. of $7.5 \mathrm{Ci} / \mathrm{mmol}$ (New England Nuclear, Boston, MA); Insulin Radioimmunoassay Kits (Amersham Corporation, Arlington Heights, IL); and male golden hamsters (100-125 g) (Engel Laboratory, Inc., Farmersburg, IN).

The following chemicals were gifts: tranylcypromine sulphate (Smith, Kline and French Laboratory, Philadelphia, PA); and $\mathrm{N}^{1}$ (DL-seryl)- $\mathrm{N}^{2}(2,3,4$-trihydroxybenzyl) hydrazine (RO-4-4602) (Hoffmann-La Roche Co., Nutley, NJ).

\section{Experimental Procedure}

The hamsters had access to food and water until the time of sacrifice. All medications were administered by IP injection. The dose and timing of administration of the drugs prior to sacrifice were: tranylcypromine $25 \mathrm{mg} / \mathrm{kg}$ at 48 and $24 \mathrm{~h} ; \mathrm{RO}-4-4602400 \mathrm{mg} / \mathrm{kg}$ at $2 \mathrm{~h}$; and DOPS $120 \mathrm{mg} / \mathrm{kg}$, L-DOPA $65 \mathrm{mg} / \mathrm{kg}$ and 5-hydroxytryptophan $30 \mathrm{mg} / \mathrm{kg}$ at $1 \mathrm{~h}$.

The hamsters were sacrificed by decapitation and blood was collected into heparin. After sacrifice, the pancreas was removed and pancreatic islets were isolated by a modified collagenase digestion technique [9]. The tissue was digested in Hanks' balanced salt solution $(\mathrm{pH}, 7.4)[10]$. When islets were obtained for monoamine measurements, collagenase digestion was continued until they were completely free of any strands of acinar tissue. It was found, however, that when islets were obtained for insulin secretion studies, it was important to use the minimal exposure to collagenase that would give free islets. Therefore, some of the islets had small strands of acinar tissue attached. The islets for norepinephrine and dopamine analysis were homogenized in $0.1 \mathrm{~mol} / 1$ percloric acid in a ground-glass homogenizer. The islets for serotonin analysis were homogenized in $0.1 \mathrm{~mol} / 1 \mathrm{HCl}$. The islets for assay for MAO activity were homogenized in $0.15 \mathrm{~mol} / \mathrm{l}$ potassium chloride.

Insulin secretion studies were carried out by incubating islets in modified Krebs Ringer Bicarbonate (KRB) buffer ( $\mathrm{pH}, 7.4$ ) with a nonstimulatory concentration of glucose $(3.3 \mathrm{mmol} / 1)$, sodium pyruvate $(5 \mathrm{mmol} / \mathrm{l})$, sodium fumarate $(5 \mathrm{mmol} / \mathrm{l})$, sodium glutamate $(5 \mathrm{mmol} / \mathrm{l})$, and bovine serum albumin $(4 \mathrm{~g} / \mathrm{l})$. Ten islets were placed in a $12-75 \mathrm{~mm}$ test tube in $1 \mathrm{ml}$ of incubation fluid.
All incubations were subsequently carried out under an atmosphere of $95 \% \mathrm{O}_{2}$ and $5 \% \mathrm{CO}_{2}$. The incubations were performed at $37^{\circ} \mathrm{C}$ in a reciprocally shaking water bath. After the first $15 \mathrm{~min}$ of incubation, the islets were allowed to settle and media was aspirated off and discarded ("preincubation"). One ml of fresh medium, containing $3.3 \mathrm{mmol} / 1$ glucose was added to the islets and they were incubated for a second $15 \mathrm{~min}$ period ("first incubation"). At the conclusion of this incubation, the islets were allowed to settle and aliquots of medium were removed for measurement of insulin. The remaining medium was aspirated off. In the third $15 \mathrm{~min}$ period, $1 \mathrm{ml}$ of medium, containing either 3.3 or $16.6 \mathrm{mmol} / \mathrm{l}$ of glucose was added to the islets ("second incubation"). At the conclusion of this incubation, the islets were allowed to settle and aliquots of medium were removed for measurement of insulin. The insulin response of the islets in this incubation to 3.3 and $16.6 \mathrm{mmol} / 1$ glucose was compared in each of the experimental groups of hamsters.

\section{Analytical Methods}

The MAO activity of the islet homogenates was determined with a sensitive radioassay that employed ${ }^{14} \mathrm{C}$-tryptamine $(0.2 \mathrm{mmol} / \mathrm{l})$ as a substrate (lower limits of sensitivity $50 \mathrm{pmol}$ product $/ \mathrm{mg}$ tissue/ $\min$ ) [11]. The protein content of the homogenate was determined with a colorimetric method [12]. The norepinephrine [8, 13], dopamine $[3,14]$, and serotonin $[4,15]$ concentrations in the islets were determined with previously described sensitive and specific radioassays in which a ${ }^{3} \mathrm{H}$-labelled methyl group is transferred from ${ }^{3} \mathrm{H}$-S-adenosylmethionine to the monoamine under investigation by a semipurified enzyme. After appropriate isolation, the amount of purified radioactive derivative that was generated was determined in a liquid scintillation counter. The lower limit of sensitivity of the norepinephrine assay was 0.3 to $0.6 \mathrm{pmol}$ norepinephrine/assay tube and there was less than $2 \%$ cross reactivity with dopamine and serotonin or DOPS. The lower limit of sensitivity of the dopamine assay was 1 to 2 pmol dopamine/assay tube and there was less than $3 \%$ cross reactivity with norepinephrine, serotonin or L-DOPA. The lower limit of sensitivity of the serotonin assay was 4 to 8 pmol of serotonin/assay tube and there was less than $1 \%$ cross reactivity with norepinephrine, dopamine or 5-hydroxytryptophan. The wet weight of the islets was calculated on the basis of their protein content being $15 \%$ of their wet weight [16]. The monoamine content of the tissues was expressed as $\mu \mathrm{mol} / \mathrm{kg}$ wet weight. Plasma and medium insulin concentrations were determined with a double antibody radioimmunoassay method [17]. Beef insulin was used as the insulin standard. To minimize the problem that the binding curves for hamster and beef insulin are not perfectly parallel, aliquots of plasma and medium were selected that would fall in the midportion of the standard curve. Plasma glucose was determined with a glucose oxidase method [18]. The plasma insulin glucose ratios $(\mathrm{I} / \mathrm{G})$ were calculated according to the method of Seltzer et al. [19]. To reduce variation in experimental technique, all islet incubation studies were performed by one operator. All norepinephrine measurements were made by a second operator, all dopamine measurements by a third operator, and all serotonin measurements by a fourth operator.

\section{Statistical Methods}

Unless otherwise stated, data are given as mean \pm SEM. The statistical significance of differences between two groups (i. e. the difference in the release of insulin in the second incubation to 3.3 and $16.6 \mathrm{mmol} / 1$ glucose) was sought with Students' $t$ test. When more than one experimental group was being compared to a con- 
Table 1. In vivo effect of injections of tranylcypromine and monoamine precursors on plasma glucose, insulin and insulin glucose ratio of the golden hamster

\begin{tabular}{|c|c|c|c|c|c|c|c|c|c|}
\hline & Control & Tran & DOPS & $\begin{array}{l}\text { Tran } \\
+ \\
\text { DOPS }\end{array}$ & $\begin{array}{l}\text { Tran } \\
+ \\
\text { RO-4-4602 } \\
+ \\
\text { DOPS }\end{array}$ & L-DOPA & $\begin{array}{l}\text { Tran } \\
+ \\
\text { L-DOPA }\end{array}$ & 5-HTP & $\begin{array}{l}\text { Tran } \\
+ \\
\text { 5-HTP }\end{array}$ \\
\hline $\begin{array}{l}\text { Plasma glucose } \\
(\mathrm{mmol} / \mathrm{l})\end{array}$ & $6.6 \pm 0.6$ & $6.8 \pm 0.7$ & $12.0 \pm 1.0^{b}$ & $24.3 \pm 2.6^{b}$ & $11.7 \pm 2.1$ & $7.9 \pm 0.6$ & $18.6 \pm 2.8^{b}$ & $6.3 \pm 0.4$ & $14.9 \pm 1.94^{b}$ \\
\hline $\begin{array}{l}\text { Plasma insulin } \\
(\mu \mathrm{U} / \mathrm{ml})\end{array}$ & $45 \pm 8$ & $43 \pm 6$ & $69 \pm 10$ & $25 \pm 7$ & $28 \pm 9$ & $54 \pm 21$ & $15 \pm 2^{\mathrm{a}}$ & $50 \pm 11$ & $16 \pm 4^{\mathrm{a}}$ \\
\hline $\begin{array}{l}\text { Plasma insulin } \\
\text { glucose ratio }\end{array}$ & $7.0 \pm 1.2$ & $7.2 \pm 1.4$ & $5.7 \pm 0.7$ & $1.1 \pm 0.3^{b}$ & $2.3 \pm 0.4^{\mathrm{a}}$ & $7.1 \pm 2.7$ & $0.9 \pm 0.4^{b}$ & $8.4 \pm 2.0$ & $1.1 \pm 0.2^{b}$ \\
\hline
\end{tabular}

\footnotetext{
a Significantly different from control, $\mathrm{p}<0.05 ; \quad$ b Significantly different from control, $\mathrm{p}<0.01$
}

Plasma glucose and insulin was determined on control hamsters and hamsters receiving the NE precursor DL-threo-dihydroxyphenylserine (DOPS), the dopamine precursor L-3,4 dihydroxyphenylalanine (L-DOPA) or the serotonin precursor 5-hyroxytryptophan (5-HTP). Some hamsters were pretreated with the monoamine oxidase inhibitor tranylcypromine (Tran) and/or the decarboxylase inhibitor RO-44602. The animals were in the fed state at the time of sacrifice. Values are given as the mean \pm SEM of six experiments

\section{INSULIN SECRETION}

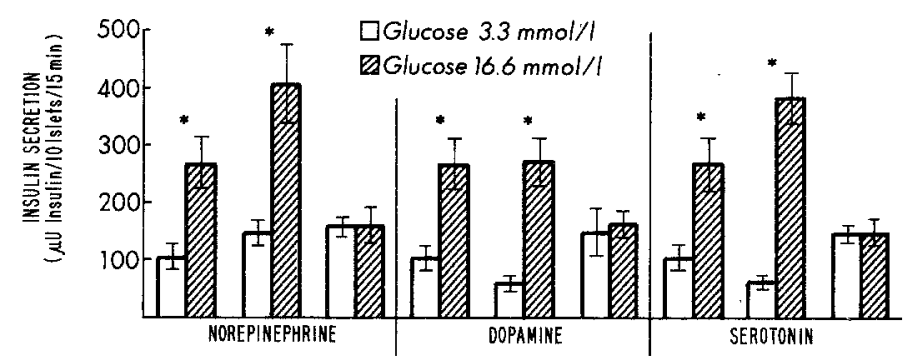

Fig. 1. Comparison of monoamine concentration and glucose-stimulated insulin secretion of pancreatic islets isolated from hamsters treated with the monoamine precursors DL-threo-dihydroxyphenylserine (DOPS), L-3,4-dihydroxyphenylalanine (L-DOPA), or 5-hydroxytryptophan with and without pretreatment with tranylcypromine (TRAN). Each value for monoamines represents the mean \pm SEM of data from 5 to 8 hamsters. The asterisk (*) indicates the concentration of monoamines in the islets of treated hamsters is significantly higher than the concentration in islets of control hamsters. The insulin secretion data, which is obtained from the second incubation, is plotted on a linear scale. Each bar resrepresents the mean and the bracket the SEM of measurements from 10 to 20 tubes of islets. The islets in each incubation experiment depicted were obtained from four hamsters. The asterisk $\left({ }^{*}\right)$ indicates that there was greater insulin secretion stimulated by 16.6 than $3.3 \mathrm{mmol} / 1$ glucose trol group, the data was subjected to analysis of variance [20]. The significance of the differences between mean values was estimated using the single-tailed multiple comparisons test of Scheffe [20].

\section{Results}

Table 1 compares the plasma glucose, plasma insulin, and the plasma insulin glucose ratio in control hamsters and in hamsters which received monoamine precursors with and without pretreatment with the monoamine oxidase inhibitor tranylcypromine. The tranylcypromine resulted in an $88 \%$ mean inhibition of islet monoamine oxidase at the time the hamsters were sacrificed. Tranylcypromine alone had no effect on plasma glucose or plasma insulin levels, or the plasma insulin glucose ratio. DOPS alone increased plasma glucose levels but did not significantly alter the plasma insulin or plasma insulin glucose ratio. When DOPS was administered to hamsters that were pretreated with tranylcypromine, there was a much greater rise in plasma glucose and a decrease in the plasma insulin glucose ratio. These alterations were partially prevented when the hamsters received the decarboxylase inhibitor RO-4-4602 prior to the administration of DOPS. L-DOPA or 5-hydroxytryptophan alone had no effect on plasma glucose, plasma insulin, or the plasma insulin glucose ratio. When L-DOPA or 5-hydroxytryptophan were administered to hamsters that were pretreated with tranylcypromine, there was an increase in plasma glucose and a decrease in plasma insulin levels and the plasma insulin glucose ratio.

To determine if the various monoamine precursors altered basal insulin secretion, in vitro insulin 
secretion in the first incubation from islets isolated from control hamsters was compared with the secretion from islets isolated from treated hamsters. The mean \pm SEM insulin secretion, expressed as $\mu \mathrm{U}$ insulin/10 islets/15 min, were: control $158 \pm 32$; DOPS $169 \pm 26$; tranylcypromine plus DOPS $178 \pm 22$; tranylcypromine plus RO-4-4602 plus DOPS $211 \pm$ 38; L-DOPA $37 \pm 5$; tranylcypromine plus LDOPA $144 \pm 27 ;$ 5-hydroxytryptophan $214 \pm 44$; and tranylcypromine plus 5-hydroxytryptophan 170 \pm 26 . The only treatment group that significantly differed from the control group was the L-DOPA group $(\mathrm{p}<0.01)$.

Figure 1 compares the in vitro insulin secretory response to glucose stimulation (upper panel, linear plot) with the monoamine concentration (lower panel, numbers) of islets isolated from control hamsters with islets isolated from hamsters treated with monoamine precursors with and without tranylcypromine. The insulin secretion data was obtained from the second incubation period. Glucose at $16.6 \mathrm{mmol} / 1$ stimulated the secretion of a greater amount of insulin from islets of control hamsters than $3.3 \mathrm{mmol} / \mathrm{l}$ glucose ( $271 \pm 47$ vs $102 \pm 22 \mu \mathrm{U} / 10$ islets $/ 15 \mathrm{~min}$, $\mathrm{p}<0.01$ ). The monoamine concentrations in control hamster islets, in $\mu \mathrm{mol} / \mathrm{kg}$ wet weight, were: norepinephrine $42 \pm 8$; dopamine $8 \pm 2$; and serotonin $26 \pm 9$. Tranylcypromine administration did not alter islet monoamine concentration. Islets obtained from tranylcypromine treated animals had a significantly greater insulin response to $16.6 \mathrm{mmol} / \mathrm{lglu}$ cose $(240 \pm 18 \mu \mathrm{U}$ insulin $/ 10$ islets $/ 15 \mathrm{~min})$ than to $3.3 \mathrm{mmol} / 1$ glucose $(128 \pm 6 \mu \mathrm{U}$ insulin $/ 10$ islets/ 15 min, $\mathrm{p}<0.01$ ). DOPS alone caused a 1.9 -fold increase in islet norepinephrine, but did not impair insulin secretion. When DOPS was administered to hamsters that were pretreated with tranylcypromine, there was a 3.5 -fold increase in islet norepinephrine and inhibition of glucose stimulated insulin secretion. When tranylcypromine pretreated hamsters received the decarboxylase inhibitor RO-4-4602 prior to DOPS, there was no increase in islet norepinephrine concentration and the insulin secretory response of the islets was maintained. L-DOPA and 5-hydroxytryptophan alone resulted in a 6-fold increase in dopamine and a 22-fold increase in serotonin respectively, but did not impair insulin secretion. When LDOPA and 5-hydroxytryptophan were administered to hamsters that were pretreated with tranylcypromine, there was a 85 -fold increase in dopamine and a 59-fold increase in serotonin respectively, with marked impairment of insulin secretion.

The hamsters that received the monoamine precursors after pretreatment with tranylcypromine, that had a marked impairment of in vitro glucose stimu- lated insulin secretion, were hyperglycaemic at the time of sacrifice. To rule out the possibility that the impaired in vitro insulin secretion of these hamsters was due to a depletion in the pancreatic insulin pool from hyperglycaemia, we treated two control hamsters with $250 \mathrm{mg}$ of intraperitoneal glucose $30 \mathrm{~min}$ prior to sacrifice. Despite the fact that their plasma glucose was 15.6 and $16.2 \mathrm{mmol} / \mathrm{l}$ at the time of sacrifice, in vitro insulin secretion from their islets was not impaired.

\section{Discussion}

In the present study the islet norepinephrine, dopamine and serotonin concentrations were increased by administering the respective amino acid precursors of these monoamines. Previous studies demonstrated that these amino acid precursors are taken up by the islets by an active energy requiring process [7]. They are then converted to their respective amine by the aromatic amino acid decarboxylase of the pancreatic islets [21]. The predominant enzyme found in islets that inactivates monoamines is monoamine oxidase [8]. The degradation of the monoamines can be markedly decreased by the administration of a monoamine oxidase inhibitor such as tranylcypromine. Thus, the islet monoamine concentration can be even further increased by administering the monoamine precursors to animals that were pretreated with tranylcypromine.

Animals that received the monoamine precursor after pretreatment with tranylcypromine had marked hyperglycaemia. Although this may, in part, be due to extrapancreatic effects of monoamines such as stimulation of hepatic glycogenolysis and gluconeogenesis, the decreased plasma insulin concentration and the decreased plasma insulin glucose ratio indicates an impairment of pancreatic insulin secretion. At the time of sacrifice, the experimental groups that received the monoamine precursor after pretreatment with tranylcypromine had the most marked impairment in in vivo insulin secretion as well as the greatest elevation in pancreatic islet monoamine concentration.

Despite the marked increase in islet monoamine concentration in the hamsters receiving the monoamine precursor after tranylcypromine pretreatment, there was no impairment in in vitro basal insulin secretion. The only treatment schedule that appeared to decrease the basal insulin secretion was L-DOPA alone. Although the administration of the monoamine precursor alone did not alter glucose-stimulated in vitro insulin secretion, the administration of the monoamine precursor to animals pretreated with 
tranylcypromine resulted in marked impairment of such insulin secretion. Using the perfused rat pancreas, other investigators have noted that serotonin inhibits glucose-stimulated insulin secretion but does not alter basal insulin secretion [22].

Using histochemical fluorescence techniques, other investigators have demonstrated a relationship between islet monoamines and impaired insulin secretion. Lernmark could not identify serotonin fluorescence in the islets of control mice [23]. However, when he administered 5-hydroxytryptophan to mice pretreated with the monoamine oxidase inhibitor nialamide, their islets had intense fluorescence characteristics of serotonin. The in vitro insulin secretory response to glucose was completely abolished in islets microdissected from mice treated in this manner.

We felt it would be worthwhile to evaluate the relationship between the islet monoamine concentration and islet insulin secretion with the present quantitative techniques of monoamine assay. Recent reports indicate that measurement of rat brain norepinephrine and dopamine by histochemical fluorescence does not always accurately reflect the content of these monoamines by quantitative chemical analysis [24]. The eye of the invertebrate, Aplysia, was recently demonstrated to have large amounts of serotonin measured by gas chromotography mass spectrometry which was not detected by histochemical fluorescence [25]. Therefore, although histochemical fluorescence data is valuable for assessing the role of monoamines, the results may be only semi-quantitative in some tissues.

In the present study, glucose-stimulated insulin secretion was not impaired by moderate increases in islet monoamines induced by administration of the monoamine precursor without tranylcypromine pretreatment. It is not known if physiological variations in islet cell monoamines modify insulin secretion. Lundquist et al recently presented compelling evidence that variation in islet cell serotonin does not play a role in the storage and secretion of insulin from guinea pig islets [26, 27]. Even if islet monoamines do not play a role in the physiological control of insulin secretion they may play a role in the islet response to drug therapy. Patients receiving LDOPA therapy for Parkinson's Disease have an impairment in early insulin secretion [28]. Recently L-DOPA has been given in conjunction with the monoamine oxidase inhibitor deprenyl to retard the degradation of dopamine in the basal ganglia of brain [29]. It is conceivable that this combination of drugs may result in a greater accumulation of islet monoamines and further impairment in early phase insulin secretion. Further studies will be needed to delineate the role that different intracellular monoamines (norepinephrine, dopamine and serotonin) may play in regulating insulin secretion in various animal species in physiological and pathological states.

Acknowledgements. This study was supported by the Veterans Administration and NIH Chinese Hamster Program Project 08PI AM 21933A01. We are grateful for the technical assistance of Ms. Judith A. Blalock and the secretarial assistance of Mrs. Cynthia M. Cox.

\section{References}

1. Lebovitz HE, Feldman J M (1973) Pancreatic biogenic amines and insulin secretion in health and disease. Fed Proc 32: 1797-1802

2. Cegrell L (1968) The occurence of biogenic monoamines in the mammalian endocrine pancreas. Acta Physiol Scand [Suppl] 314: 1-60

3. Zern RT, Foster LB, Blalock JA, Feldman JM (1979) Characteristics of the dopaminergic and noradrenergic systems of the pancreatic islets. Diabetes 28: 185-189

4. Bird J L, Wright EE, Feldman J M (in press) Pancreatic islets a tissue rich in serotonin. Diabetes

5. Cegrell L (1970) Monoaminergic mechanisms in the pancreatic A-cells. In: Falkmer S, Hellman B, Täljedal I B (eds) The structure and metabolism of the pancreatic islets. Pergamon Press, Oxford, p 131-138

6. Tjalve H (1971) Catechol- and indolamines in some endocrine cell systems. Acta Physiol Scand [Suppl] 360: 8-20

7. Mahony C, Feldman JM (1977) Species variation in pancreatic islet monoamine uptake and action. Diabetes 26: 257-261

8. Feldman J M, Henderson J H, Blalock J A (1979) Effect of pharmacological agents and fasting on pancreatic islet norepinephrine in the golden hamster. Diabetologia 17: 169-174

9. Feldman J M, Chapman B (1975) Preparation of islets of Langerhans from rabbits and hamsters by the collagenase digestion technique. Acta Diabetol Lat 12: 208-218

10. Hanks JH, Wallace RE (1949) Relations of oxygen and temperature in preservation of tissues by refrigeration. Proc Soc Exp Biol Med 71: 196-200

11. Wurtman RJ, Axelrod J (1963) A sensitive and specific assay for the estimation of monoamine oxidase. Biochem. Pharmacol 12: 1439-1441

12. Lowry OH, Rosenbrough NJ, Farr AL, Randall RJ (1951) Protein measurements with the Folin phenol reagent. J Biol Chem 193: 265-275

13. Henry D P, Starman B J, Johnson D G, Williams R H (1975) A sensitive radioenzymatic assay for norepinephrine in tissues and plasma. Life Sci 16: 375-384

14. Coyle J T, Henry D (1973) Catecholamines in fetal and newborn rat brain. J Neurochem 21: 61-67

15. Saavedra J M, Brownstein M, Axelrod J (1973) A specific and sensitive enzymatic-isotopic microassay for serotonin in tissues. J Pharmacol Exp Ther 186: 505-515

16. Hellerstrom C, Brolin SE (1975) Biochemistry and biophysics of insulin secretion. In: Hesselblat A, Bruchhausen F U (eds) Handbook exp. phar., XXXIV-2. Springer, Berlin Heidelberg New York, p 57-78

17. Hales CN, Randle PJ (1963) Immunoassay of insulin with insulin antibody precipitate. Biochem J 88: 137-146

18. Saifer A, Gerstenfeld B (1958) Photometric micro determination of blood glucose with glucose oxidase. J Lab Clin Med 5: $448-460$ 
19. Seltzer HS, Allen EW, Herron AL Jr, Brennan MT (1967) Insulin secretion in response to glycemic stimulus: relation of delayed initial release to carbohydrate intolerance in mild diabetes mellitus. J Clin Invest 46: 323-335

20. Zar J H (1974) Biostatistical analysis. Englewood Cliffs, N. J., Prentice Hall, p 130-143, 159-161

21. Lebovitz HE, Downs Jr RW (1973) Catecholamine biosynthesis enzymes in pancreatic islet cells. In: Usidin E, Snyder $\mathrm{SH}$ (eds) Frontiers in catecholamine research. Pergamon Press, Oxford, p 831-833

22. de Bold ML, Bencosme SA (1978) Effects of serotonin and its antagonists on the first phase of insulin release in normal and hypersomatotropic rats. Horm Metab Res 10: 500-505

23. Lernmark A (1971) The significance of 5-hydroxytryptamine for insulin secretion in the mouse. Horm Metab Res 3: 305-309

24. Kopin IJ, Palkovitz M, Kobayashi RM, Jacobowitz DM (1974) Quantitative relationship of catecholamine content and histofluorescence in brain of rats. Brain Res 80: 229-235

25. Corrent G, MacAdoo D J, Eskin A (1978) Serotonin shifts the phase of the circadian rhythm from the Aplysia eye. Science 202: 977-979
26. Lundquist I, Sundler F, Hakanson R, Larsson LI, Heding L G (1975) Differential changes in 5-hydroxytryptamine and insulin content of guinea pig B-cells. Endocrinology 97: 937-947

27. Lundquist I, Hakanson R, Sundler F, Heding LG (1978) 5Hydroxytryptamine and insulin storage mechanisms. Diabetologia 15: 251

28. Boyd AE, Lebovitz HE, Feldman J M (1971) Endocrine function and glucose metabolism in patients with Parkinson's Disease and their alteration by L-DOPA. J Clin Endocrinol Metab 33: 829-837

29. Lees AJ, Kohout LJ, Shaw KM, Stern GM, Elsworth JD, Sandler M, Youdin MBH (1977) Deprenyl in Parkinson's disease. Lancet II: 791-795

Received: August 3, 1979, and in revised form: December 6, 1979

Jerome M. Feldman, M. D.

Box 2963

Duke University Medical Center

Durham, NC 27710

USA 